\title{
Desenvolvimento de um sistema de aquisição de dados e de controle para a realização de ensaios de emissão de elétrons
}

\section{Development of a data acquisition and control system for electron emission tests}

Roberto F. Iannini ${ }^{1}$, Francisco T. Degasperi², Helder J. Ceragioli ${ }^{1}$, Mauro V. Amorim³ ${ }^{3}$, Alfredo C. Peterlevitz ${ }^{1}$,

Vitor Baranauskas ${ }^{1}$, Hudson Zanin ${ }^{1}$

\section{RESUMO}

Foi desenvolvido um sistema automático de aquisição e controle de dados para viabilizar a caracterização da emissividade eletrônica em catodos frios em câmara de ultra alto vácuo. O circuito desenvolvido conta com uma interface USB e porta de comunicação RS-232 virtual, sendo comando programado em Matlab. A instrumentação desenvolvida teve como motivação: i) aumentar a confiabilidade dos procedimentos de leitura da corrente de emissão em amostras de materiais nanoestruturados; ii) garantir a reprodutibilidade dos ensaios; iii) preservar a integridade das amostras e do próprio instrumento; iv) mitigar erros existentes no processo de aquisição dos dados; v) prover uma família de curvas de forma automatizada para diferentes regiões de amostra e assim estudar uniformidade. Os principais desafios encontrados durante os trabalhos relacionaram-se com a definição da topologia do circuito de entrada, da forma da isolação galvânica, interferências e tratamento dos dados adquiridos. A instrumentação desenvolvida foi testada e os resultados são apresentados neste trabalho.

Palavras Chaves: Instrumentação; Aquisição de dados; Matlab; Porta USB; Arco Voltaico; Ensaio de emissão de campo; Campo elétrico; Câmara de vácuo.

\begin{abstract}
An automatic data acquisition and control system was developed to enable the characterization of electronic emissivity of cold cathodes in ultra-high vacuum chamber. The circuit developed has USB interface and RS-232 virtual communication port commanded by Matlab program. The instrumentation was motivated: i) increase the reliability of results of field emission current in nanostructured samples; ii) ensure the reproducibility of the tests; iii) preserve the integrity of the samples and the instrument itself; iv) mitigating any errors in the process of data acquisition; v) providing an automated family of curves for different regions of a sample and studying its uniformity. The main challenges encountered during the works were related with the definition of the input circuit topology, the form of galvanic isolation, interference and treatment of acquired data. The instrumentation was tested and the results are presented here.
\end{abstract}

Keywords: Instrumentation; Data acquisition; Matlab; USB connection; Voltaic arc;. Field emission test; Electric field; Vacumm Chamber.

'Carbon Sci-Tech lab - Universidade Estadual de Campinas- Faculdade de Engenharia Elétrica e de Computação - Campinas (SP) - Brazil 2 Laboratório de Tecnologia do Vácuo - Centro Estadual de Educação Tecnológica Paula Souza - Faculdade de Tecnologia de São Paulo - São Paulo (SP) - Brazil Autor correspondente: Hudson Zanin - Carbon Sci-Tech labs - Universidade Estadual de Campinas - Faculdade de Engenharia Elétrica e de Computação Av. Albert Einstein, 400 


\section{INTRODUÇÃO}

O Carbon Sci-Tech labs desenvolve pesquisas no campo do desenvolvimento de novos materiais nanoestruturados baseados em nanotubos, nanodiamantes, grafenos e outros. Esses materiais são produzidos sobre diferentes substratos, geometrias, condições de temperatura, pressão e composição da atmosfera em reatores de deposição de filme por vapor $(\mathrm{CVD})^{(1-5)}$.

A identificação das possíveis aplicações desses novos materiais depende preliminarmente de uma caracterização física de suas propriedades elétricas e mecânicas. A depender dos resultados encontrados, esses materiais podem se tornar interessantes para aplicações na biologia, medicina, engenharias e outras áreas ${ }^{(6,7)}$.

A análise da emissividade a frio por campo elétrico para os filmes nanoestruturados é realizada na câmara de ultra alto- vácuo desenvolvida neste mesmo laboratório. A necessidade do vácuo é para redução do espalhamento dos elétrons dentro da câmara. Essa câmara agrega também outras funcionalidades tais como um espectrômetro de massa que permite identificar desde entrada de ar externo para o interior (falha de vedações) até a identificação dos principais compostos presentes na amostra em análise ${ }^{(8,9)}$. As possibilidades de aplicação de uma câmara de ultra alto vácuo como a disponível no laboratório são múltiplas e poderão contemplar até mesmo a funcionalidade de um microscópio de tunelamento eletrônico (STM $)^{(10)}$.

\section{OBJETIVO}

O objetivo deste trabalho foi o projeto e o desenvolvimento do sistema de aquisição de dados e de controle para o levantamento de curvas de emissão de elétrons a partir da utilização na câmara de ultra alto vácuo, em virtude da necessidade de instrumentação específica para complementação do instrumental acoplado à câmara.

Inicialmente se vislumbrou utilizar dispositivos comercialmente disponíveis para efetuar o controle da tensão e a aquisição de dados da corrente de emissão de campo. Durante esse processo constatou-se a dificuldade de se adaptar diversos dispositivos distintos para compor o sistema, de forma que se vislumbrou a oportunidade de desenvolvimento do hardware, firmware e software específicos para compor um sistema funcionalmente harmônico para a referida câmara.

Os objetivos deste trabalho podem ser segmentados nas seguintes etapas:

- Estudo da câmara de ultra alto vácuo e das topologias possíveis para o sistema de aquisição de dados;

- Realização de ensaios e testes de diferentes topologias de circuitos eletrônicos;

- Desenvolvimento dos circuitos, firmware e software;

- Testes de desempenho em bancada e na câmara de vácuo.

Para entender melhor a problemática faremos uma breve discussão teórica.

\section{EMISSIVIDADE ELETRÔNICA}

O fenômeno da emissão de elétrons por campo elétrico foi observado em 1897, e seu modelamento teórico foi inicialmente apresentado por W. Schottky. Ele partiu da premissa de que a emissão de elétrons somente ocorreria se o potencial aplicado superasse aquele de ligação do elétron ao material sólido. O potencial de ligação é denominado barreira de potencial. Posteriormente foi observado que campos elétricos muito menores também poderiam dar início ao processo de emissão de elétrons por campo elétrico ${ }^{11}$. Tal processo, conhecido por tunelamento quântico, é incompatível aos ensinamentos da mecância clássica, por isso causou muito alvoroço ao longo do seu entendimento.

R. H. Fowler e L. W. Nordheim desenvolveram uma teoria de campo baseada no efeito de tunelamento eletrônico. Essa teoria descreve a dependência entre a corrente de emissão de campo e a função trabalho $\Phi$, que é a energia necessária para remover o elétron do material. A função trabalho está relacionada com a barreira de potencial, sendo a primeira igual à segunda multiplicada pela carga do elétron. O processo de emissão eletrônica a frio difere da emissão térmica e da emissão fotoelétrica na medida em que não depende de excitação externa para que seja iniciada ${ }^{(12)}$.

\section{Aparato para emissão}

O aparato necessário para a realização dos ensaios de emissão eletrônica a frio encontra-se ilustrado na Figura 1. É composto por uma fonte de alta tensão variável; um medidor de corrente isolado e protegido contra surtos; um sistema de controle e aquisição de dados; uma câmara de vácuo.

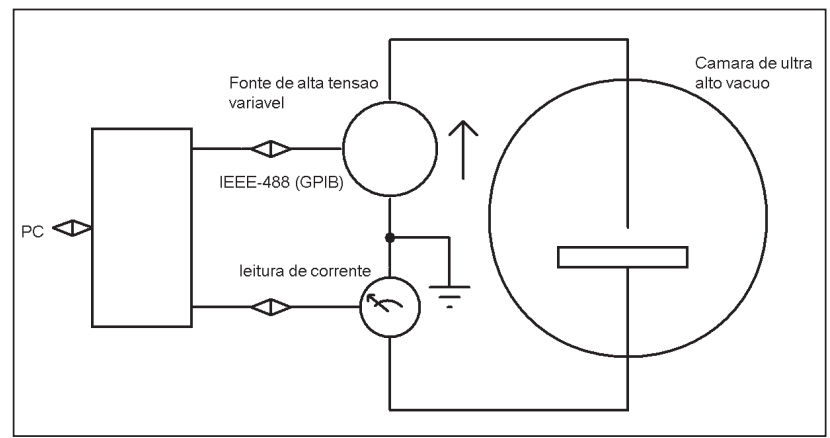

Figura 1: Esquemático do aparato para realização do ensaio de emissão eletrônica em câmara de ultra alto vácuo.

Uma fonte de alta tensão variável é utilizada para a obtenção de um potencial elétrico entre o substrato (catodo), no qual se localiza o material emissor de elétrons, e uma ponta metálica (anodo), localizada imediatamente acima do substrato.

A montagem do catodo e do anodo encontra-se dentro de uma câmara de ultra alto vácuo, que pode atingir uma pressão de até $10^{-10}$ mbar. O fenômeno da emissão eletrônica a frio pode ser observado em pressões inferiores a $10^{-6} \mathrm{mbar}$.

A câmara possui um micrômetro que permite o ajuste do espaçamento entre os eletrodos, o que possibilita - a partir da variação da diferença de potencial aplicada entre os eletrodos e da variação 
de distância entre eles - que seja possível obter uma família de curvas de emissividade eletrônica para uma dada amostra.

\section{Características da corrente de emissão}

A medição da corrente de emissão de elétrons para um dado espaçamento é realizada a partir da aplicação de uma rampa de tensão, que normalmente se inicia em poucos Volts e pode exceder 1.000 Volts. As correntes obtidas podem variar de mA a nA.

Caso haja alguma movimentação mecânica entre os eletrodos e esses venham a se curto-circuitar, ou a diferença de potencial seja elevada até o ponto de ruptura do dielétrico, ocorrerá um curto-circuito ou um arco Voltaico, que poderia facilmente danificar a instrumentação de medição, pois a corrente de circulação se elevaria instantaneamente até que:

- Ocorresse a descarga da energia acumulada nos capacitores do filtro da fonte DC de alta tensão;

- Alguma forma de interrupção da corrente fosse acionada.

Além das condições citadas, o sistema de aquisição de dados precisa operar em um ambiente sujeito à circulação de correntes parasitas na malha de terra, em função das características construtivas da câmara de vácuo (corpo metálico de dimensões consideráveis, com mais de um possível caminho para condução de correntes espúrias).

\section{Topologias para o estágio de leitura de corrente de emissão}

As características e desempenho de um amplificador de sinais construído em torno de um amplificador operacional podem ser significativamente modificadas em função da configuração de sua malha de realimentação. A depender do circuito adotado pode-se buscar maior estabilidade do sistema, melhor resposta em frequência, menor distorção ou minimização de não linearidades ${ }^{13}$. Fundamentalmente, essas características podem ser exploradas por meio de variações na arquitetura do laço de realimentação negativa do amplificador diferencial. A seguir são abordadas algumas arquiteturas que poderiam ser adotadas no estágio de leitura de corrente de emissão de campo.

\section{Shunt}

A partir da configuração de amplificador não-inversor, ilustrada na Figura 2, é possível obter-se a leitura da corrente de entrada por

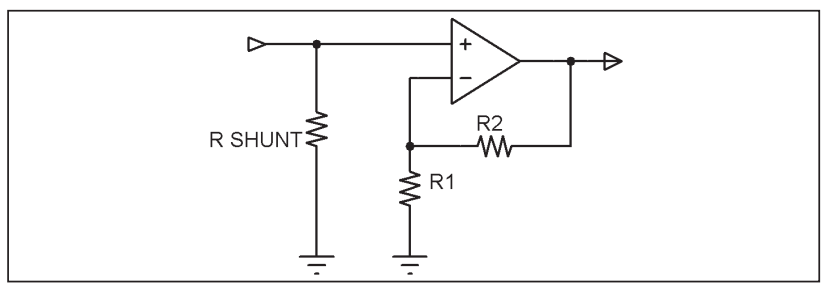

Figura 2: Conversor corrente-tensão utilizando a configuração de amplificador não-inversor. meio da relação linear $\mathrm{v}_{\text {saida }}=\left(\mathrm{i}_{\text {entrada }} \times \mathrm{R}_{\text {shunt }}\right) \cdot \mathrm{A}$, onde $\mathrm{A}=1+\left(\mathrm{R}_{2} / \mathrm{R}_{1}\right)$. Porém, para se efetuar leituras de correntes muito baixas, da ordem de nanoamperes, seria necessário: um ganho muito alto (majoração do valor da resistência do estágio amplificador.

\section{Amplificador de transimpedância}

Uma configuração mais interessante é a do amplificador de transimpedância como conversor corrente-tensão, ilustrada na Figura 3, para a qual obtém-se a leitura da corrente de entrada por meio da relação $\mathrm{v}_{\text {saida }}=\left(\mathrm{i}_{\text {entrada }} \times \mathrm{R}_{\text {shunt }}\right)$. A entrada inversora do amplificador operacional apresenta tensão muito próxima a zero Volts, em razão do terra virtual formado pela malha de realimentação.

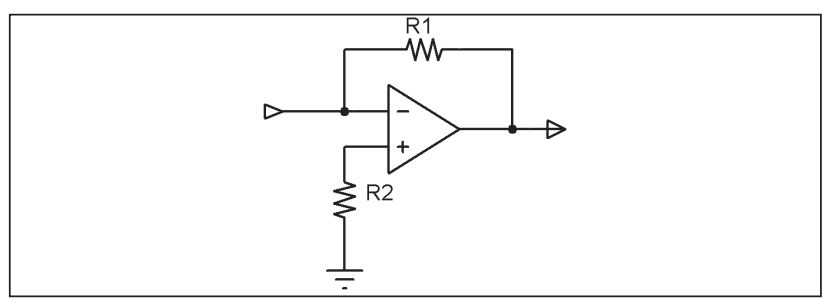

Figura 3: Conversor corrente-tensão utilizando a configuração de amplificador de transimpedância.

O ruído proveniente do resistor, na entrada não inversora, pode ser acoplado ao terra por meio de um capacitor de by-pass. Isso não é possível na configuração não-inversora, pois a entrada não inversora faz parte da malha de sinal. Os resistores do estágio de leitura de corrente desempenham um importante papel na qualidade do sinal de saída, como será analisado a seguir.

\section{Ruído na malha de realimentação}

Resistor de ligas de carbono e cerâmicas contidas entre dois contatos metálicos nas extremidades tem o ruído de contato predominante frente às demais fontes. Tal ruído é causado pelas junções ôhmicas. Quando não há corrente circulando pelo resistor, o ruído total gerado neste se aproxima do ruído térmico.

Já o tipo de resistor menos ruidoso é o de fio (usualmente uma liga de níquel e cromo ao redor de um núcleo de fibra de vidro, cerâmica ou plástico) no qual o ruído total gerado decorre praticamente do ruído térmico ${ }^{(14)}$. O espalhamento do elétron entre grãos é mais favorável em ligas metálicas do que em metais.

Outro fator que afeta o desempenho dos resistores é a potência de operação para a qual foram projetados. Comparando-se dois resistores, um de $2 \mathrm{~W}$ e outro de $1 / 2 \mathrm{~W}$ de mesma resistência, sendo precorridos pela mesma intensidade de corrente, aquele de maior potência de operação apresenta nível de ruído até três vezes menor que o outro. Isso ocorre em função da diferença da geometria entre os resistores, que afeta a parcela de ruído de contato ${ }^{(15)}$.

Para baixas frequências predomina o ruído de contato, ou $1 / f$, cujo aumento é inversamente proporcional à frequência, conforme ilustrado na Figura 4. É causado pela variação da 
condutividade em função de imperfeições nos contatos entre os diferentes materiais e ocorre em qualquer junção entre dois materiais condutores distintos devido à diferença entre os níveis Fermi e das funções trabalho.

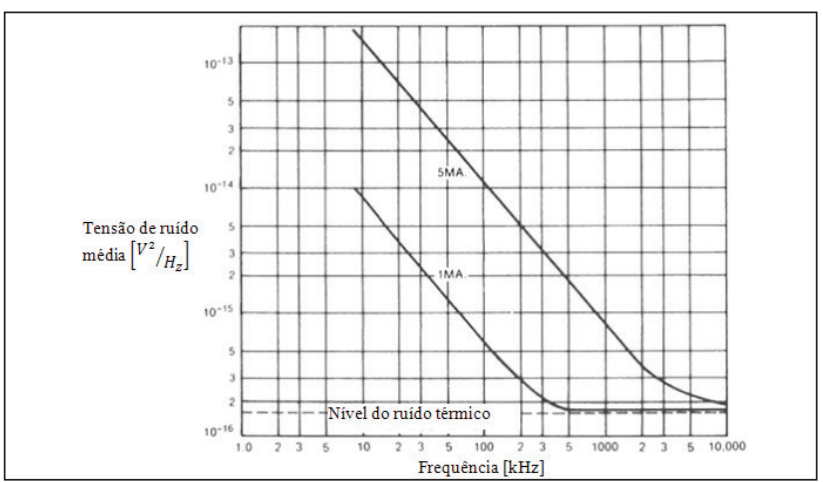

Figura 4: Variação da tensão de ruído intrínseca a um resistor de $10 \mathrm{k}$ de carbono em função da corrente e da frequência ${ }^{(16)}$.

\section{Modelamento do ruído no amplificador}

Um modelo para os ruídos presentes em um amplificador operacional encontra-se ilustrado na Figura 5.

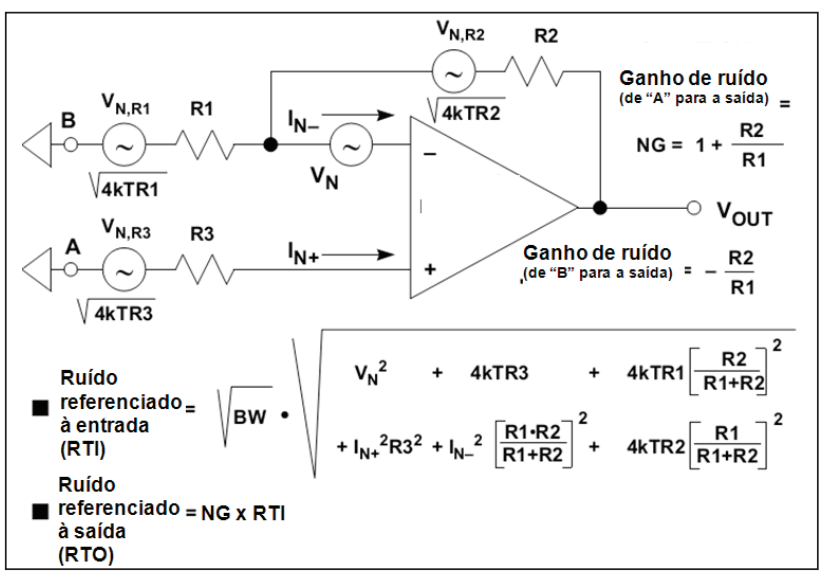

Figura 5: Modelo de ruído para um amplificador operacional em configuração genérica ${ }^{(17)}$.

RTI é o ruído referenciado a partir da entrada (Referred to Input) e evidencia a contribuição da corrente de ruído fluindo através dos resistores da malha. RTO é o ruído referenciado à saída (Referred to Output), e representa o ruído de entrada multiplicado pelo ganho de ruído do amplificador (Noise Gain). A tensão do ruído Johnson associado a cada um dos resistores encontra-se representada pelas fontes de tensão $\mathrm{V}_{\mathrm{N}, \mathrm{R} 1}$ a $\mathrm{V}_{\mathrm{N}, \mathrm{R} 3}$, sendo $\mathrm{V}_{\mathrm{N}}$ o ruído intrínseco ao amplificador operacional.

A tensão de ruído de amplificadores operacionais pode variar desde $1 \mathrm{nV} / \sqrt{\mathrm{Hz}}$ a $20 \mathrm{nV} / \sqrt{\mathrm{Hz}}$ ou mais. Amplificadores operacionais com entradas tipo bipolar tendem a apresentar uma tensão de ruído mais baixa que amplificadores operacionais com JFET nas entradas, apesar de ser possível a construção de amplificadores JFET com baixa tensão de ruído, tais como o AD743 e o AD 745, ao "custo" de maior área de silício e mais capacitância na entrada, e consequente restrição da resposta em frequência ${ }^{(18)}$.

A corrente de ruído intrínseca em amplificadores operacionais pode variar desde $0,1 \mathrm{fA} / \sqrt{ } \mathrm{Hz}$ a $5 \mathrm{pA} / \sqrt{ } \mathrm{Hz}$ ou mais, e é preponderante quando o amplificador operacional encontra-se conectado em uma malha de realimentação que possibilite sua passagem através da impedância de realimentação, o que resultará em uma tensão de ruído.

\section{Proteção contra sobretensão}

Quando da ocorrência de um arco Voltaico dentro da câmara ou de um curto-circuito entre o eletrodo emissor e o eletrodo coletor, uma corrente elétrica de alta intensidade flui em direção ao estágio de leitura de corrente de emissão, que deve possuir um mecanismo para suportá-la.

Uma forma de se mitigar o risco de dano ao estágio de entrada em função da probabilidade de ocorrência de arcos Voltaicos é a inserção de um circuito de proteção em série com a entrada do conversor corrente-tensão, como ilustrado na Figura 6.

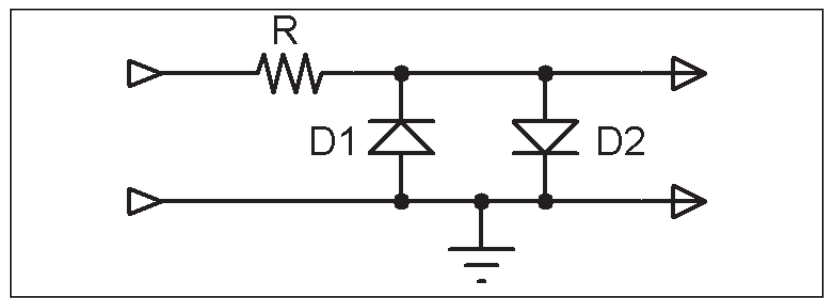

Figura 6: Diodos conectados em oposição após um resistor limitador de corrente de curto-circuito(19).

O estágio de leitura de corrente deve necessariamente apresentar em condições normais de operação uma queda de tensão desprezível entre seus terminais, para que nenhum dos diodos entre em condução devido ao fluxo de corrente que está fluindo para dentro do amplificador operacional.

$\mathrm{O}$ arranjo supracitado requer diodos de baixa fuga, necessários para a minimização do erro inserido no sistema (corrente de fuga). O diodo FDH333 possui uma corrente de fuga máxima de $1 \mathrm{nA}$ e uma capacidade de surto de $4 \mathrm{~A}$ (condução direta), e suportou as descargas ocorridas na câmara de vácuo durante a realização dos ensaios de emissão eletrônica.

Com relação ao resistor limitador de corrente, seu efeito no circuito é o de aumentar a diferença de potencial (Voltage burden) entre os terminais do sistema de medição de corrente elétrica, em relação à saída da câmara. Não há uma maneira ideal de se determinar um valor para a queda de tensão nos terminais desse resistor. Seu valor deve ser grande o suficiente para proteger os diodos da ruptura por sobrecarga. Como diretriz, uma boa prática é utilizar um valor suficientemente grande para causar uma queda de $1 \mathrm{~V}$ quando o medidor de corrente estiver operando no fundo de escala ${ }^{(19)}$. 
Por fim, os diodos precisam ser mantidos em completa escuridão, pois seu encapsulamento de vidro os torna fotossensíveis, o que pode acabar gerando correntes parasitas no circuito.

\section{Resposta em frequência e outros aspectos}

Caso se optasse pela configuração de amplificador não-inversor e resistor shunt, o sinal de saída estaria sujeito a erros de leitura por diferenças nas tensões de polarização (offset) das entradas do amplificador operacional, o que ensejaria ajuste na determinação do zero Volt da saída do amplificador. Poderia haver também uma queda de tensão excessiva no resistor de mensuração da corrente. Em ambas as situações, o desempenho em frequência do circuito estaria severamente limitado em função da carga elétrica armazenada na capacitância intrínseca de entrada do circuito (referente aos cabos e ao conjunto formado por catodo-vácuo-anodo).

Outro problema encontrado nessa configuração seria a forma de se implementar uma proteção contra surtos na entrada quando da ocorrência de arcos voltaicos dentro da câmara de vácuo, pois essa configuração necessitaria de uma tensão na entrada para que fosse possível efetuar a leitura de corrente. Logo, o circuito de proteção contra sobretensão apresentado anteriormente não seria de grande valia, pois os diodos conectados em oposição entrariam em condução.

Já para a configuração de amplificador de transimpedância adotada para se efetuar a leitura da corrente de emissão, a impedância de entrada do amplificador é muito próxima a zero, assim como o potencial na entrada. Consequentemente, não haverá energia armazenada no capacitor equivalente de entrada, ou seja: não é necessário que o sinal de entrada carregue e descarregue a capacitância equivalente de entrada, o que melhora a resposta em frequência do circuito de leitura de corrente, conforme ilustrado na Figura 7.

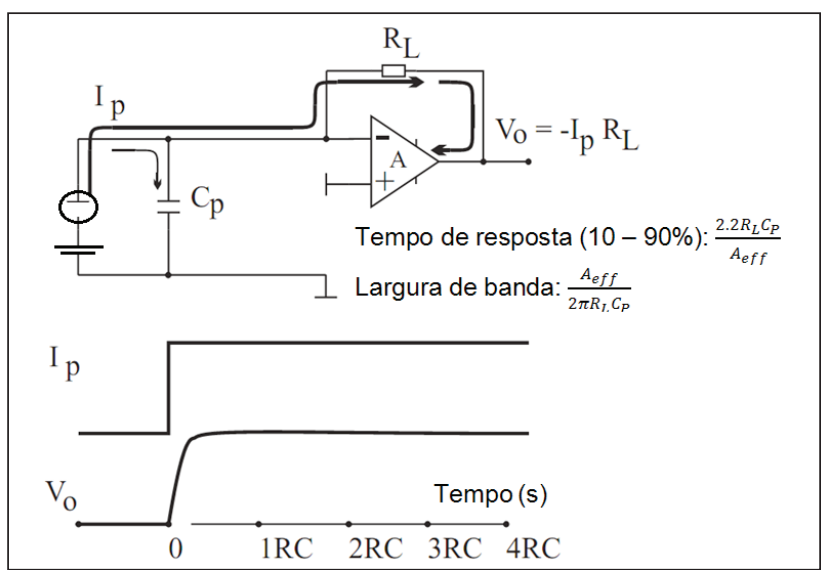

Figura 7: Amplificador de transimpedância - resposta ao degrau de tensão(20).

Para o amplificador de transimpedância, o modelamento do ruído pode ser simplificado, uma vez que tanto o ruído Johnson $\mathrm{i}_{\mathrm{N}_{\mathrm{th}}}$, ruído shot $\mathrm{i}_{\mathrm{N}_{\mathrm{s}}}$ e o ruído de corrente intrínseco à entrada do amplificador $\mathrm{i}_{\mathrm{N}}$ podem ser considerados como fontes de corrente em paralelo, conectadas à entrada inversora, conforme ilustra a Figura 8.

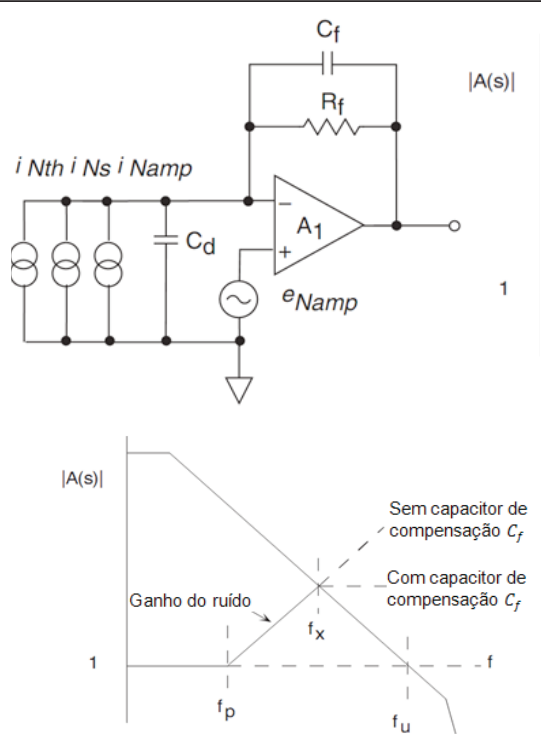

Figura 8: Modelamento do ruído e resposta em frequência ${ }^{(21)}$.

Dessa maneira, todas as fontes de corrente terão o mesmo tratamento, sendo:

- $\mathrm{i}_{\mathrm{N}_{\text {th }}}-\mathrm{O}$ ruído Johnson intrínseco ao resistor de realimentação negativa, $\mathrm{R}_{\mathrm{f}}$. Observe-se que esse ruído aparece na realidade em paralelo com o referido resistor, mas em função da baixa impedância de entrada do amplificador de transimpedância (aproximadamente zero ohm) pode ser convenientemente modelado como uma fonte de corrente em paralelo com a entrada do amplificador;

- $\quad \mathrm{i}_{\mathrm{N}_{\text {shot }}}-\mathrm{O}$ ruído shot ou ruído de contato decorrente da passagem de corrente elétrica por $\mathrm{R}_{\mathrm{f}}$.

- $\mathrm{i}_{\mathrm{N}_{\text {amp }}}$ - O ruído intrínseco da entrada do amplificador operacional;

- $\mathrm{i}_{\text {entrada }}-\mathrm{O}$ sinal de interesse (corrente de emissão de campo proveniente da câmara de vácuo) aparece em paralelo com as fontes de ruído.

A única fonte de ruído que enseja tratamento diverso das demais é $\mathrm{e}_{\mathrm{N}_{\mathrm{amp}}}$. Como a saída do amplificador é a diferença dos sinais entre as entradas não inversora e inversora, a fonte de ruído pode ser modelada em qualquer um desses terminais. Arbitrou-se por considerá-la junto à entrada não inversora em função da facilidade de sua modelagem (para se obter sua contribuição como fonte de ruído, basta multiplicar $\mathrm{e}_{\mathrm{N}_{\mathrm{amp}}}$ pelo ganho da entrada não inversora, $\mathrm{A}_{\mathrm{VCL}}$ ).

Por inspeção da topologia do circuito, o ganho é dado por $\mathrm{A}_{\mathrm{VCL}}=\mathrm{A}_{\mathrm{VoL}} / 1+\left(\mathrm{A}_{\mathrm{voL}} / 1+j \omega \mathrm{C}_{\mathrm{d}} \mathrm{Z}_{\mathrm{f}}\right)$, onde: $\mathrm{A}_{\mathrm{voL}}=$ Ganho do amplificador em malha aberta do amplificador operacional selecionado; $\mathrm{Z}_{\mathrm{f}}=$ Impedância complexa do laço de realimentação negativa $\left(\mathrm{C}_{\mathrm{f} /} / \mathrm{R}_{\mathrm{f}}\right)$. 
A tensão de ruído $\mathrm{e}_{\mathrm{N}_{\mathrm{m}}}$ representa pouca influência em baixas frequências, mas à medida que a frequência aumenta, sua influência passa a ser majoritária e compromete o desempenho do amplificador.

A capacitância de entrada $C_{d}$ introduz um polo na frequência $\mathrm{f}_{\mathrm{p}}=1 /\left(2 \pi \mathrm{R}_{\mathrm{f}} \mathrm{C}_{\mathrm{d}}\right)$ na função de transferência do ganho do ruído, conforme ilustrado no diagrama de Bode (plot $|\mathrm{Z}| v s \mathrm{f}$ ). Caso não houvesse compensação de frequência (capacitor $\mathrm{C}_{\mathrm{f}}$ ) o ângulo de defasagem na frequência de interseção $f_{x}$ causaria instabilidade e oscilação do estágio amplificador. Por meio da inclusão de o circuito se torna estável em função da inclusão de um zero em $f_{x}=1 /\left(2 \pi R_{f} C_{d}\right)$.

A inclusão de $\mathrm{C}_{\mathrm{f}}$ no estágio amplificador tem como efeito colateral uma pequena diminuição da frequência do polo, que pode ser desprezada fazendo-se $\mathrm{C}_{\mathrm{f}}<<\mathrm{C}_{\mathrm{d}}$. A frequência $\mathrm{f}_{\mathrm{x}}$ marca $\mathrm{o}$ encontro entre a reta ascendente a partir de $\mathrm{f}_{\mathrm{p}}$ e a reta descendente de ganho do amplificador operacional, que intercepta o eixo das abscissas na frequência $f_{u}$ (quando o amplificador exibe ganho unitário). Daí tem-se que $\mathrm{f}_{\mathrm{x}}=\sqrt{\mathrm{f}_{\mathrm{p}} \cdot \mathrm{f}_{\mathrm{U}}}$

É comum encontrar relatos sobre a dificuldade de se fazer funcionar um amplificador de entrada na configuração de transimpedância ${ }^{(20) .}$ Um amplificador com realimentação negativa implementada por meio de um resistor e que possua uma elevada capacitância em sua entrada inversora, seja ela em função dos cabos ou em função da própria capacitância da saída da câmara de vácuo, deve mesmo oscilar próximo à frequência pois o deslocamento de fase causado por $\mathrm{C}_{\mathrm{d}} \cdot \mathrm{R}_{\mathrm{f}}$ soma-se ao deslocamento de fase intrínseco do próprio amplificador operacional e em alguma frequência alta deverá implicar em realimentação positiva. Se o ganho para essa frequência for superior à unidade, o amplificador de transimpedância oscilará.

Na prática, o melhor valor de $C_{f}$ para se evitar a oscilação pode ser encontrado variando-se empiricamente seu valor em torno de alguns picofarads. Porém, comercialmente é difícil encontrar capacitores de baixa capacitância. Uma solução prática para esse problema de compensação de frequência é a construção de um capacitor por meio da utilização de um par trançado isolado, como por exemplo, cabo para wire-wrap, conectado aos terminais do resistor de realimentação, conforme ilustra a Figura 9.

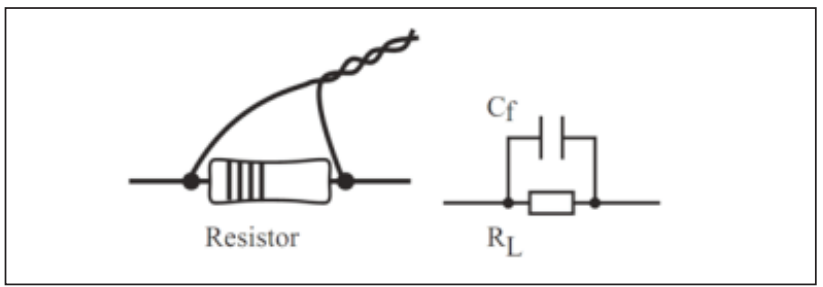

Figura 9: Implementação de um capacitor de baixa capacitância em paralelo com o resistor da malha de realimentação(20).

Essa implementação para o capacitor é conveniente do ponto de vista prático, pois seu valor pode ser ajustado na bancada, reduzindo-se (cortando) gradualmente o comprimento do par trançado até que se observe no osciloscópio o ponto ótimo de resposta em frequência.

\section{Outras topologias possíveis}

Não obstante a escolha da topologia do conversor correntetensão implementado por meio de um amplificador operacional, no qual a malha de realimentação força a entrada do circuito para uma tensão muito próxima a zero Volts, as topologias abaixo descritas são também interessantes para se implementar o estágio de leitura de corrente de emissão de campo e merecem ser examinadas.

\section{Amplificador cascode}

O circuito para aferição da corrente de emissão de campo na câmara de vácuo possui uma capacitância intrínseca $C_{d}$ que restringe a resposta em frequência do amplificador de transimpedância. Uma forma alternativa de se aumentar a resposta em frequência do estágio de entrada seria por meio da adoção da configuração "cascode".

Nessa configuração, a capacitância de entrada permanece relativamente isolada do laço de realimentação em razão da configuração de base comum do transistor da entrada (Figura 10), que também exibe melhor resposta em frequência que o amplificador operacional.

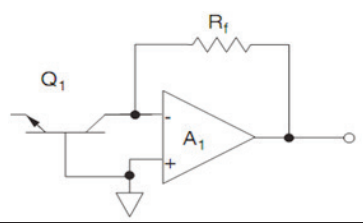

Figura 10: Amplificador cascode implementado a partir de um amplificador operacional(21).

No modelo de transistor de Ebers-Moll, a resistência de emissor $r_{E}$ para pequenos sinais é dada por: $r_{E}=k_{T} / e i_{C}$, onde: $k_{T} / e$ é aproximadamente $25 \mathrm{mV}$ a temperatura ambiente e $r_{E}$ é a resistência intrínseca do emissor do transistor.

O transistor transfere a corrente de emissor para o coletor e, ao mesmo tempo, mantém a tensão do emissor relativamente constante. $\mathrm{O}$ laço da realimentação negativa do amplificador operacional fica desobrigado de servir como caminho para a corrente necessária para carregar e descarregar a capacitância intrínseca da saída da câmara de emissão de campo.

O laço de realimentação do amplificador operacional está exposto à capacitância $C_{o b}$ do transistor e à própria capacitância da entrada inversora, que somadas ainda representam um valor menor que a capacitância $C_{d}$ da saída da câmara de emissão de campo (composta pela capacitância do cabo de saída e também do porta-substrato).

\section{Amplificador logarítmico}

Um amplificador logarítmico é útil para instrumentação em sistemas cujo sinal de entrada varie por várias ordens de grandeza 
e necessitam ser medidos de forma contínua, isto é, sem ajustes discretos de ganho.

O transistor no laço de realimentação, na Figura 11, opera na região de condução direta $\left(V_{C B}=0 \mathrm{~V}\right)$ Nessa condição a tensão base-emissor de um transistor bipolar está relacionada com a corrente de coletor de forma logarítmica.

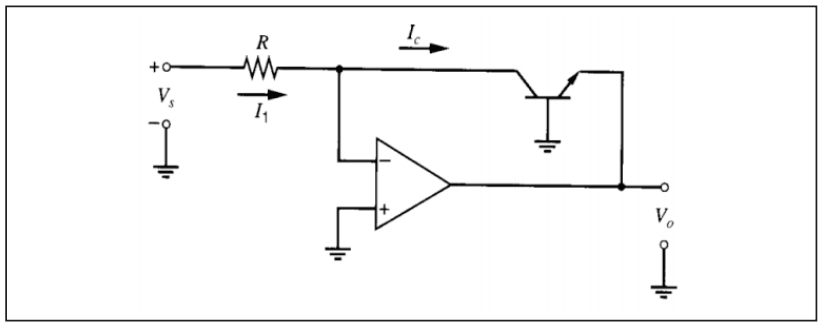

Figura 11: Amplificador logarítmico(22).

A configuração do amplificador operacional ainda é a de amplificador de transimpedância (isto é: a entrada é um sinal de corrente e a saída um sinal de tensão). Como a entrada não inversora encontra-se conectada ao neutro do sistema (zero Volt), o transistor da realimentação é forçado pelo sinal de tensão da saída a conduzir a corrente de entrada integralmente, de forma a equalizar o potencial na entrada inversora (terra virtual). A presença de um transistor no laço de realimentação implica em uma característica logarítmica de corrente de coletor. Logo, a tensão de saída do amplificador operacional também acompanhará a envoltória dessa curva, possibilitando assim um amplificador capaz de funcionar continuamente para sinais cuja faixa dinâmica se estenda por várias ordens de grandeza, observada equação: $V_{o}=-V_{T} \ln \left(v s / I_{c} R\right)$. Alternativamente, o transistor no laço de realimentação pode ser substituído por um diodo, uma vez que sua reposta de corrente também segue uma curva logarítmica $^{(19)}$.

Uma desvantagem dessa configuração é a precisão em razão da curva logarítmica, uma vez que a resolução do conversor analógico/digital seria prejudicada para sinais de maior amplitude.

\section{Integrador}

Para medição de carga elétrica ou corrente elétrica de baixa intensidade, pode-se utilizar a configuração de integrador implementado com o auxílio de um amplificador operacional, conforme ilustrado na Figura 12.

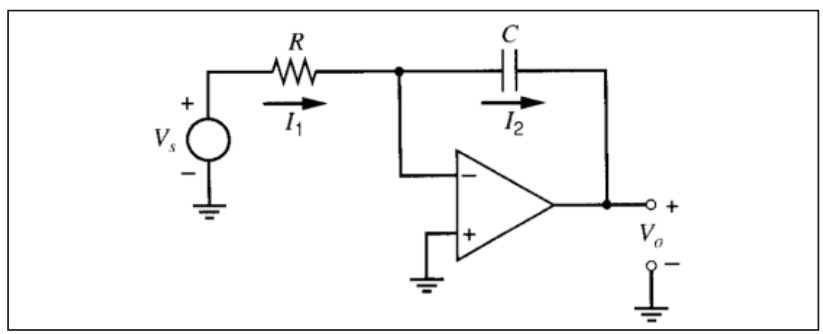

Figura 12: Integrador ${ }^{(22)}$.
O integrador não utiliza elemento resistivo no laço de realimentação. O resistor de entrada indicado no esquema serve apenas para que seja desenvolvida uma corrente proporcional à tensão de entrada. Por não haver elemento resistivo no laço de realimentação, a configuração do integrador está livre do ruído Jonhson.

Essa é a configuração mais adequada para a medição de correntes extremamente baixas $\left(10^{-12}\right.$ a $\left.10^{-15} \mathrm{~A}\right)$, pois a tensão resultante no capacitor presente na realimentação negativa representa a integral da corrente ao longo do tempo: $i(t)=C(d v / d t), \operatorname{logo}: v(t)=(1 / \mathrm{c}) \int_{\mathrm{t} 0}^{\mathrm{t}} i(t) d t+v\left(t_{\mathrm{o}}\right)$. A carga elétrica $Q$ pode ser prontamente conhecida por meio de $Q=C V$. Uma vantagem interessante do integrador é o fato de que interferências periódicas, como aquela provocada pela indução eletromagnética das instalações em $60 \mathrm{~Hz}$, podem ser eliminadas naturalmente durante a integralização da carga elétrica no capacitor. Para isso, é necessário observar que o intervalo de integração do capacitor deve ser um múltiplo do período do sinal da interferência ${ }^{(23,24)}$.

\section{IMPLEMENTAÇÃO DO HARDWARE}

Dentre as topologias existentes para se efetuar a leitura de corrente de emissão de campo na câmara de vácuo, optou-se pelo conversor corrente-tensão.

Existem diversos modelos de amplificadores operacionais voltados para aplicação em instrumentação, sendo desejáveis, para o caso da câmara de vácuo, as seguintes características: proteção interna contra sobretensão nos terminais diferenciais de entrada; corrente de entrada $(i)$ e corrente de ruído de entrada $\left(i_{n}\right)$ tão baixas quanto possível.

O melhor desempenho foi obtido com o amplificador operacional LMC6001. Trata-se de um circuito integrado cuja corrente de entrada é inferior a 25 fA. Sua proteção interna contra descarga eletrostática é capaz de operar em potenciais de até $2.000 \mathrm{~V}$.

Em razão de sua corrente de ruído de entrada, $i_{n}$, ser da ordem de $0,13 \mathrm{fA} / \sqrt{\mathrm{Hz}}$, sua amplificação se dá de forma praticamente sem ruído, adicionando apenas para um resistor de realimentação de $100 \mathrm{k} \Omega^{(25)}$. A tensão de ruído, referenciada na entrada é de $22 \mathrm{nv} / \sqrt{ } \mathrm{Hz}$, implicando em relação sinal ruído melhor que a maioria dos amplificadores para eletrômetro com entrada JFET.

Para se evitar correntes de fuga na montagem experimental, poderia se utilizar soquetes de PTFE, cuja resistência elétrica é superior a $10^{18} \Omega \times \mathrm{cm}^{(19)}$. Porém, uma solução mais isolante que o teflon é a montagem de todos os componentes do amplificador de transcondutância diretamente soldados um nos outros, de forma que sua sustentação mecânica se dê em razão das soldas ${ }^{(26,27)}$. Após a soldagem dos componentes, é necessário realizar uma limpeza profunda dos componentes com álcool isopropílico ou tanque de ultrassom, de forma a remover gorduras e fluxos de solda que poderiam interferir no desempenho do circuito. 
Por fim, para se evitar interferências eletromagnéticas, a montagem do amplificador de transimpedância foi encapsulada em uma folha de Mu-metal (uma liga de níquel, ferro, cobre, cromo e molibdênio), material de elevada permeabilidade magnética ${ }^{(28,29)}$.

\section{Conversão A/D}

Dentre os diversos tipos de conversores A/D disponíveis, os mais indicados para a leitura da corrente de emissão de campo são:

- Conversor sigma-delta, pois é possível aumentar a resolução em bits em detrimento da taxa de conversão, o que seria interessante para se obter uma faixa dinâmica mais ampla em detrimento da largura de banda;

- Conversor de múltiplas rampas - sua arquitetura baseia-se na medição dos tempos de carregamento e descarregamento de um capacitor e, dessa forma, pode prover o cancelamento de ruídos ainda na fase analógica de integração do sinal de entrada, desde que seja ajustada a frequência de amostragem (relógio do conversor). Essa característica é conveniente para eliminar ruídos provenientes de interferências magnéticas como, por exemplo, da rede elétrica, pois produz nulos na resposta em múltiplos da frequência de amostragem, conforme ilustrado na Figura 13.

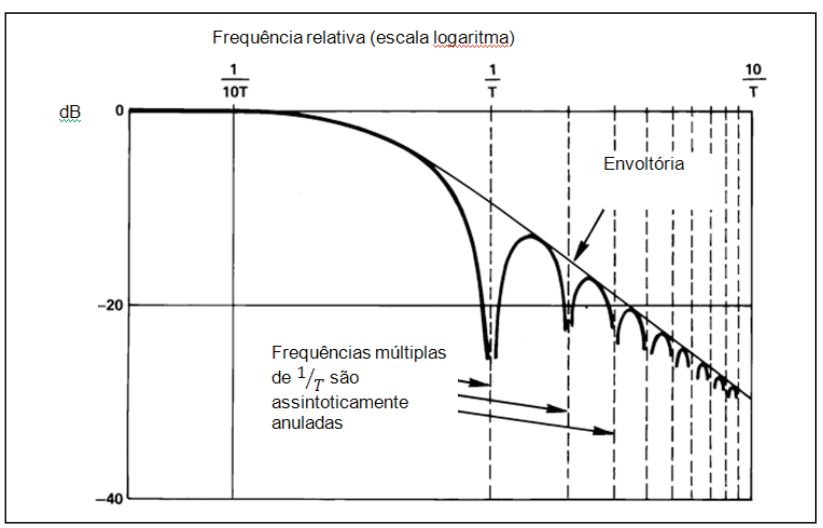

Figura 13: Nulos na resposta em frequência de um conversor de múltiplas rampas ${ }^{(30)}$.

Optou-se pela adoção do conversor integrador de múltiplas rampas TC850. Trata-se de um conversor de 15 bits de resolução mais um bit de sinal (positivo / negativo), capaz de operar em uma faixa dinâmica de $96 \mathrm{~dB}$. O TC850 utiliza uma rampa de tensão para carregamento do capacitor e duas rampas para descarga sendo a primeira rápida, gerando 9 bits de resolução, e a segunda, lenta, gerando adicionalmente mais 6 bits de resolução. Esse processo necessita de $2^{9}+2^{6}=576$ pulsos de relógio para completar a fase de descarregamento da tensão acumulada no capacitor. Um ciclo de conversão completo consome 1280 pulsos de relógio, pois antes de se iniciar a rampa de integração, ocorre um processo de ajuste de zero do integrador.
Por utilizar duas rampas para descarregar o capacitor de integração do sinal, são necessárias duas referências de tensão. A segunda necessita ser 1/64 do valor da primeira, e pode ser obtida a partir de um divisor resistivo formado por resistores moldados no mesmo encapsulamento e conectados de forma alternada, conforme ilustra a Figura 14. Essa configuração faz com que os gradientes de temperatura e variações intrínsecas de valores se cancelem mutuamente. Importante observar que não é o valor absoluto da resistência que está estabilizado, e sim a taxa de divisão de resistência que se mantém constante.

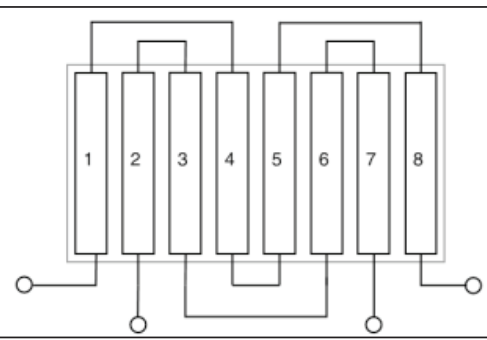

Figura 14: Divisor resistivo implantado a partir de uma rede resistiva encapsulada em um mesmo chip $^{(21)}$.

A referência de tensão para um conversor com resolução de 15 bits deve apresentar estabilidade, precisão e nível de ruído suficientes para permitir que a resolução $(100 \mu \mathrm{V})$ seja atingida em sua plenitude.

$\mathrm{Na}$ busca por uma referência de tensão suficientemente adequada, optou-se pela utilização da AD780, que apresenta nível de ruído na banda de baixa frequência $(0,1 \mathrm{a} 10 \mathrm{~Hz})$ em torno de $20 \mu \mathrm{Vp}$-p quando se utiliza capacitores de by-pass tanto na saída quanto no pino de compensação de temperatura.

Com respeito aos capacitores conectados ao conversor $A / D$, tanto para integração do sinal quanto das referências de tensão, foram utilizados capacitores de poliéster, em razão da baixa corrente de fuga desse tipo de dielétrico. Essa é uma característica necessária, dada a baixa energia acumulada para fazer funcionar os ciclos de integração e descarga.

\section{Microcontrolador}

Algumas características particularmente convenientes do PIC18F4680, adotado no desenvolvimento da instrumentação, são as funcionalidades internamente implementadas por meio dos módulos de Capture/Compare/PWM (CCP1) e de Enhanced Capture/Compare/PWM (ECCP1), que, combinados, permitem gerar o sinal de relógio para o conversor A/D sem onerar o firmware.

O módulo de comunicação serial, USART, foi utilizado para comunicação com uma ponte USB da RS232 e diversas portas de entrada/saída para controle e aquisição de dados do conversor A/D externo.

Observou-se que, devido ao baixo consumo, mesmo quando operando em frequência nominal, o microcontrolador não representou uma carga relevante frente ao restante do circuito. 


\section{O código fonte para o microcontrolador (firmware)}

Foram utilizados os seguintes programas para o desenvolvimento, testes e download do firmware para o microcontrolador:

- HI-TECH C Compiler for PIC18 MCUs ver. 9.64 utilizado para compilar o código fonte desenvolvido em C;

- $\quad$ MPLAB Integrated Development Environment ver 8.5 Utilizado para gerar o arquivo em formato de máquina (.hex), para ser transferido para a memória flash do microcontrolador;

- PicKit 2 Programmer ver 2.61 - utilizado para se efetuar a transferência e conferência do arquivo em formato de máquina para o microcontrolador.

$\mathrm{O}$ ambiente de desenvolvimento integrado MPLAB integrase com o compilador $\mathrm{C}$ e com o gravador de microcontrolador PicKit, além de encapsular de forma consistente seus comandos. Dessa forma, foram realizados os ajustes necessários para criação, compilação, debug, e gravação do firmware para o microcontrolador.

\section{Isolação galvânica e estratégia do firmware}

Uma característica fundamental da arquitetura adotada foi a isolação galvânica para eliminar a possibilidade de circulação de correntes parasitas e, ao mesmo tempo, isolar o usuário da câmara de vácuo da possibilidade de exposição eventual à alta tensão aplicada entre o catodo emissor e o anodo.

Acopladores isoladores do tipo óptico (optoisolador) são dispositivos normalmente utilizados para se isolar galvanicamente sinais lógicos. A corrente de ativação do led interno gira em torno de 20 a $60 \mathrm{~mA}$ para a maioria dos modelos disponíveis.

Como o circuito é alimentado exclusivamente pela porta USB, há disponibilidade de até $500 \mathrm{~mA}$ no lado imediatamente conectado a essa porta de comunicação. Porém, essa fonte de energia foi isolada por meio de um conversor de corrente contínua. Para minimizar interferências, é desejável manter o consumo do lado isolado o mais baixo possível, uma vez que ruídos excessivos provenientes do chaveamento ou interferências eletromagnéticas podem afetar a resolução efetiva do conversor $\mathrm{A} / \mathrm{D}^{(31)}$.

Na busca por uma solução de mais baixo consumo de energia para o isolamento galvânico dos sinais de dados e após extensa pesquisa por soluções mais econômicas do ponto de vista de corrente elétrica, optou-se pela utilização de um isolador eletromagnético AD260BND-2. Dessa forma, o consumo quiescente para as linhas de comunicação foi reduzido a $4 \mathrm{~mA}$ em cada lado, o suficiente para alimentar os circuitos dos drivers dos canais. De forma mais econômica que os optoisoladores, cada linha de sinal requer $160 \mu \mathrm{A} / \mathrm{MHz}$ do lado de entrada e $40 \mu \mathrm{A} /$ $\mathrm{MHz}$ do lado da saída (isolado).

A tensão provida pela porta USB alimenta também um conversor DC/DC, construído a partir do circuito integrado SG3524.
Uma característica interessante do isolador eletromagnético utilizado é o fato de que se encontram contidos no mesmo encapsulamento cinco isoladores de sinal, sendo três em direção ao circuito isolado e dois na direção contrária, além de um pequeno transformador isolador com derivação central, sendo conveniente para a implementação de uma solução de isolação galvânica completa. A Figura 15 ilustra as linhas de comunicação utilizadas (duas de saída e uma de entrada), bem como o arranjo necessário para o controle do conversor DC/DC.

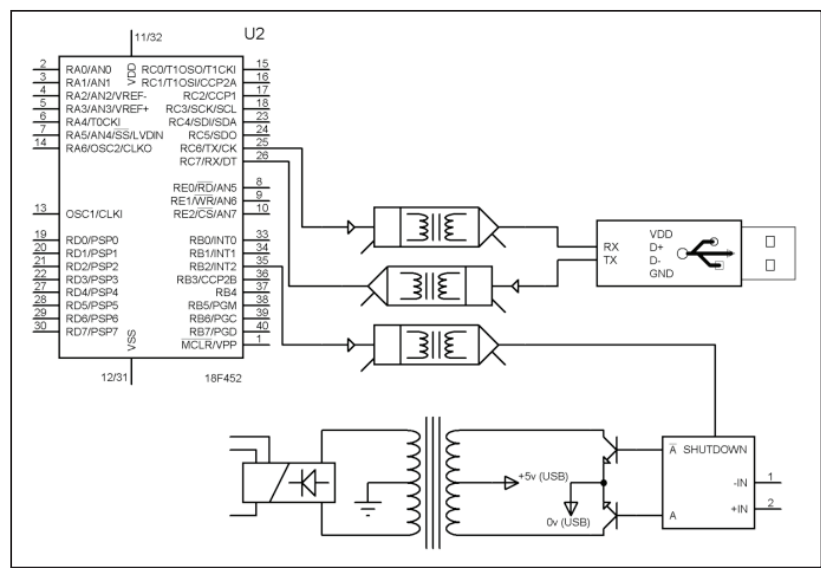

Figura 15: isolação galvânica da alimentação e das linhas de comunicação.

O circuito alternador construído para excitar o primário do transformador opera em $200 \mathrm{kHz}$. Foram utilizados diodos Schottky 1N5817, que apresentam uma queda de tensão de 0,3 Volt, importante para manter a tensão após o retificador no nível mais alto possível.

O circuito do lado da interface de usuário se encontra completamente isolado do circuito exposto à corrente de emissão de campo. Correntes de retorno por terra estão impedidas de circular pelo circuito, o que contribui para melhorar significativamente a imunidade ao ruído, pois bloqueia o caminho para eventuais correntes parasitas.

Para que não ocorra interferência eletromagnética proveniente da solução adotada para isolação galvânica entre a parte em contato com o circuito da câmara e a parte de transmissão de dados, o firmware comanda o desligamento do conversor DC/DC sempre antes do início de um ciclo de conversão $\mathrm{A} / \mathrm{D}$, cessando o funcionamento da fonte de interferência eletromagnética existente no próprio circuito.

Enquanto o conversor permanecer desligado, a tensão do circuito é provida pelos capacitores conectados logo após os diodos retificadores. Nesse momento inicia-se uma curva de descarga que faz variar a tensão nos capacitores.

Para se contornar essa instabilidade na regulação da alimentação, foram utilizados reguladores lineares de tensão de baixa queda, capazes de operar com diferença de potencial de $380 \mathrm{mV}$ para tensão positiva (LP2950ACZ-5) e de apenas $340 \mathrm{mV}$ para tensão negativa (LT1964ES5). Ambos os 
reguladores apresentam um consumo (corrente quiescente) inferior a $100 \mu \mathrm{A}$.

Observou-se a manutenção da regulação de tensão mesmo com a queda gradual da tensão nos capacitores de entrada durante o período em que o alternador permanece desligado. A tensão de alimentação devidamente regulada é então aplicada ao conversor $\mathrm{A} / \mathrm{D}$, que, após a sinalização de final de conversão, envia um sinal ao microcontrolador e esse por sua vez religa o circuito conversor DC/DC, e restaura, assim, a carga nos capacitores.

Esse ciclo é crítico, pois a capacidade de carga do capacitor após os diodos retificadores define a tensão final do circuito após o término do ciclo de conversão. A energia armazenada deve ser suficiente para possibilitar o funcionamento do conversor A/D sem ruídos ou flutuações.

Nesse ponto cabe uma ressalva acerca da possibilidade de se ter utilizado um transformador em frequência de rede para prover a alimentação do circuito. Em primeiro lugar, é preciso ter em mente que um transformador em frequência de rede emitiria interferência eletromagnética em uma faixa de frequência relativamente baixa, o que poderia vir a interferir no estágio de entrada ou no conversor A/D. Ademais, a isolação galvânica atingida em transformadores comuns raramente suporta tensões muito elevadas, da ordem de alguns quiloVolts, as quais podem ocorrer no circuito na eventualidade de um arco Voltaico ou de um curto-circuito provocado pelo usuário da câmara de vácuo durante a realização de um ensaio de emissão por campo elétrico. Assim, a utilização de um transformador em frequência de rede implicaria em mais uma conexão elétrica entre o circuito de medição de corrente de emissão e as demais partes que integram a câmara de vácuo, formando mais um caminho para possíveis correntes parasitas na malha de terra.

Minimizar a quantidade de conexões elétricas entre a câmara de vácuo e os dispositivos de suporte aos ensaios de emissão eletrônica é importante para minimizar a possibilidade de ocorrência de circulação de correntes de terra pelos diversos caminhos elétricos possíveis, daí a razão pela qual se optou por utilizar uma solução mais complexa para efetuar a alimentação do circuito.

Voltando à forma de funcionamento da alimentação do circuito desenvolvido, observa-se que cabe ao firmware decidir quando a fonte de alimentação será desligada. Poucos ciclos de relógio após o desligamento do alternador da fonte de alimentação (tempo suficiente para fazer cessar o amortecimento (ring) presente nos diodos schottky) o microcontrolador deve iniciar um ciclo de conversão A/D. Durante a conversão não há tensão de ripple na fonte de alimentação, tampouco interferência eletromagnética gerada por quaisquer partes do circuito. A Figura 16 ilustra as formas de onda obtidas durante o desenvolvimento do protótipo.

$\mathrm{Na}$ Figura 16, a forma de onda no primário encontra-se indicada pela primeira seta. A forma de onda do secundário está indicada pela segunda seta. A terceira indica a forma de onda retificada, filtrada e regulada (tensão positiva), juntamente com os ciclos gerados no firmware para desligamento/religamento do conversor A/D. A quarta seta indica que o ruído presente na forma de onda DC é de alta frequência e proveniente da forma de onda do secundário. Observe que durante os períodos de desligamento do conversor $\mathrm{DC} / \mathrm{DC}$ não há ripple. As conversões A/D são realizadas nesses ciclos.

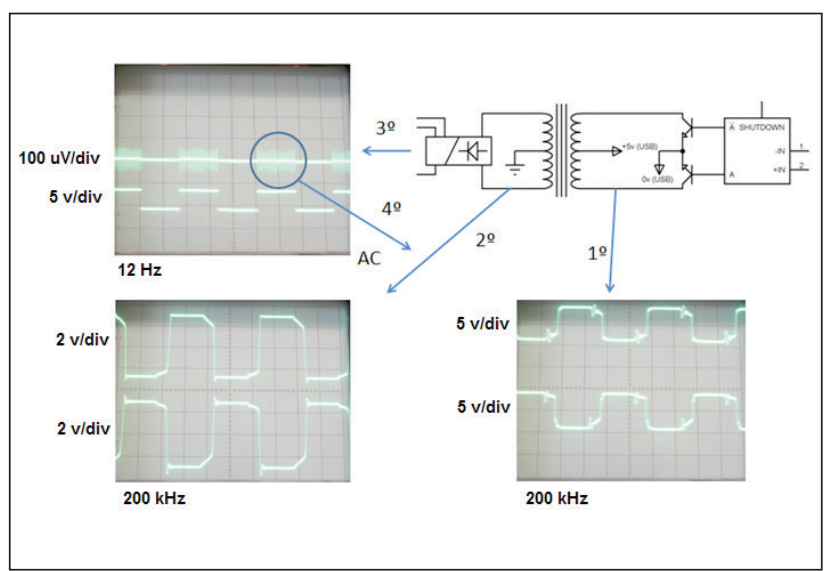

Figura 16: Ruído AC de alta frequência e ciclo de desligamento pelo do alternador.

Quanto à interferência eletromagnética da rede elétrica local, essa é eliminada em boa parte pela blindagem eletromagnética e, subsidiariamente, pelo conversor A/D durante a fase de integração do sinal, uma vez que o relógio gerado pelo microcontrolador foi deliberadamente calculado para fazer coincidir o tempo de carregamento do capacitor integrador com o tempo de duração de um ciclo da rede elétrica.

\section{SOFTWARE PARA AQUISIÇÃO DE DADOS E CONTROLE}

Concluída a descrição dos principais aspectos da arquitetura adotada para o hardware e firmware, resta ainda descrever a solução para tratamento de dados e interface com o usuário. Para tal, foram avaliadas as seguintes possibilidades para programação da interface com o usuário:

- Tool Command Language (TCL);

- Scripts em vbasic;

- Delphi ou c++ (Embarcadero);

- .net (Microsoft);

- Laboratory Virtual Instrumentation Engineering Workbench (LabView, da National instruments);

- Matrix Laboratory (Matlab, da MathWorks).

As quatro primeiras linguagens serviriam para o propósito de se implementar a interface com o usuário, com telas gráficas e geração automática de arquivos de dados em formatos comumente utilizados em programas para tratamento de dados, como o Matlab ou o Excel. Porém, em razão da necessidade de comunicação via USB com o hardware desenvolvido nesse trabalho, restaram mais interessantes as duas últimas opções 
(LabView e Matlab). Ambas oferecem suporte que excede as necessidades de controle e automação do hardware descrito. De fato, há uma série de rotinas e funcionalidades preestabelecidas que podem facilitar o desenvolvimento de código fonte para acesso e utilização do hardware desenvolvido.

O software para controle e aquisição de dados foi elaborado em Matlab em razão de sua introdução nos primeiros semestres dos cursos de engenharia, o que implica em majoração das chances de que os usuários da instrumentação aqui desenvolvida possam implantar novas rotinas para modificar, ampliar ou corrigir eventuais características de funcionamento.

Na versão 2011r2, na qual o software foi escrito, o text \& measurement toolbox (tmtool) disponibiliza uma interface para comunicação com diversos tipos de periféricos, dentre eles aqueles com porta RS-232. Esse toolbox foi utilizado durante o desenvolvimento do firmware para o microcontrolador, pois sua interface permite o envio e recebimento de bytes individualizados ou agrupados em arrays, provando-se uma ferramenta essencial durante a fase de depuração. A ponte USB utilizada no hardware é enumerada no sistema operacional Windows como uma RS-232 virtual, o que possibilitou a interface direta com o referido toolbox.

Foi definido um conjunto de comandos reservado em firmware para: iniciar a leitura; sobrestar o envio de dados; entrar em modo de comunicação para suporte à porta IEEE488 (GPIB), necessária para o controle da fonte de alta tensão 19248.

Para que o usuário possa ajustar interagir com a instrumentação, foi desenvolvida uma interface gráfica, na qual se pode ajustar os parâmetros de tensão inicial, final, incremento de tensão e, simultaneamente, registrar uma família de curvas de emissão em função da distância registrada pelo micrômetro responsável pelo espaçamento entre os eletrodos, conforme ilustrado na Figura 17.

Uma vez ajustados esses parâmetros, pode-se dar início à varredura de tensão (botão "inicia varredura de tensão"). A fonte de alta tensão executa uma sequência de comandos remotos, via interface IEEE488, de maneira sincronizada com o

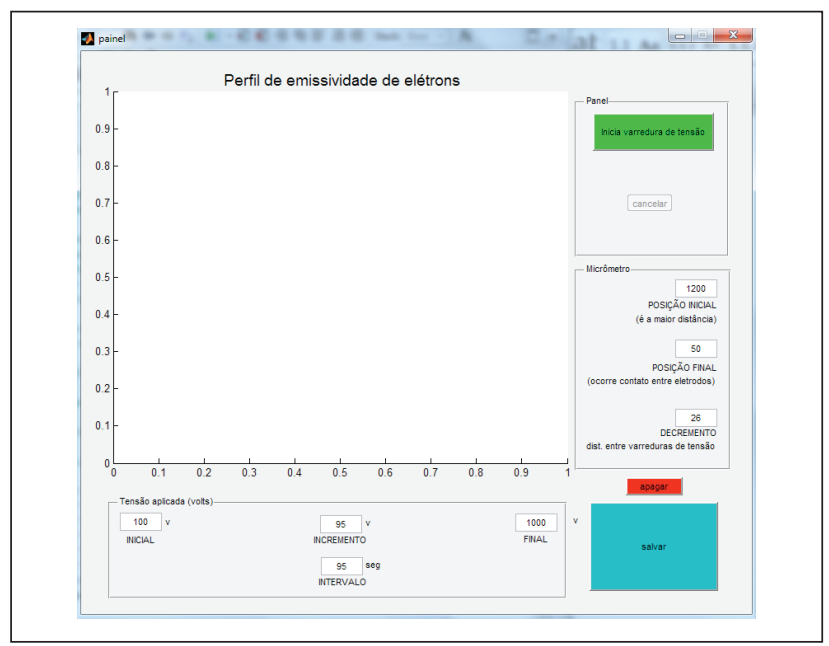

Figura 17: Tela desenvolvida para interface com o usuário microcontrolador, que por sua vez executa as leituras de corrente de emissão na câmara e sinaliza para o Matlab as ocorrências registradas quanto à sobretensão, sobrecorrente e leituras regulares. Uma vez iniciada a rampa de tensão, os dados ficam disponíveis em formato txt para que sejam tratados livremente. Ainda na tela do programa desenvolvido, é apresentado um gráfico, em tempo real, do perfil de emissividade eletrônica obtido.

No campo "micrômetro", pode-se inserir as leituras do micrômetro que ajusta a posição vertical da amostra em relação ao eletrodo coletor (anodo) de elétrons. A cada novo ajuste no micrômetro (tomando-se o cuidado de se observar a distância entre os passos) pode-se realizar uma nova leitura de emissividade eletrônica. Dessa maneira obtém-se uma família de curvas de emissividade em razão da distância entre o catodo (substrato submetido aos testes) e o anodo (eletrodo superior).

\section{RESULTADOS}

O ensaio de corrente de emissão de campo tem por objetivo investigar o comportamento da corrente de emissão em função do campo elétrico, assumindo-se o modelo de um capacitor de placas paralelas ${ }^{(32)}$

Para fins de validação da instrumentação desenvolvida e seus procedimentos operacionais, foi caracterizada uma amostra de nanotubos grafenados sobre substrato de silício em um reator pelo processo de HFCVD (Hot filament chemical vapour deposition) como descrito por Zanin ${ }^{(33)}$. Brevemente, a fonte de carbono utilizada para o crescimento é uma mistura de acetona e cânfora. A pressão no reator durante o crescimento foi de 10 torr, a temperatura de crescimento medida por um termopar, nas costas da amostra, foi de $450{ }^{\circ} \mathrm{C}$ e o tempo de crescimento de 20min. A amostra foi crescida sob uma atmosfera de nitrogênio.

A amostra preparada foi inserida na câmara de vácuo, na posição do catodo, e em seguida foi levantada, a partir da instrumentação desenvolvida, a família de curvas ilustrada na Figura 18.

Aplicando-se a equação de Fowler-Nordheim, obteve-se a comprovação de que a emissividade eletrônica se deu

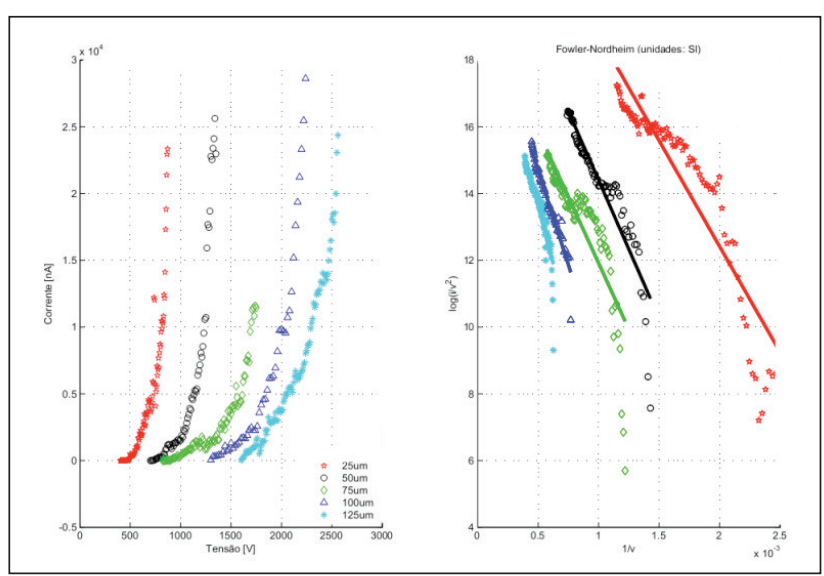

Figura 18: Perfil de emissividade traçado com o auxílio da instrumentação desenvolvida 
majoritariamente por meio de emissão a frio, uma vez que as curvas obtidas são aproximadamente retas ${ }^{(34)}$.

Por fim, para se obter a tensão de limiar em função da distância, foram adquiridos os valores de tensão e distância para uma corrente de referência de $1000 \mu \mathrm{A}$, tendo sido observado um campo elétrico de 1,16 V/ $\mu \mathrm{m}$, conforme ilustra a Figura 19. Pode-se calcular a equação da reta de forma trivial. Extrapolando-se a equação obtém-se um fator de correção da distância do eletrodo que se somado à distância lida no micrômetro encontra-se a distância efetiva entre o catodo e anodo.

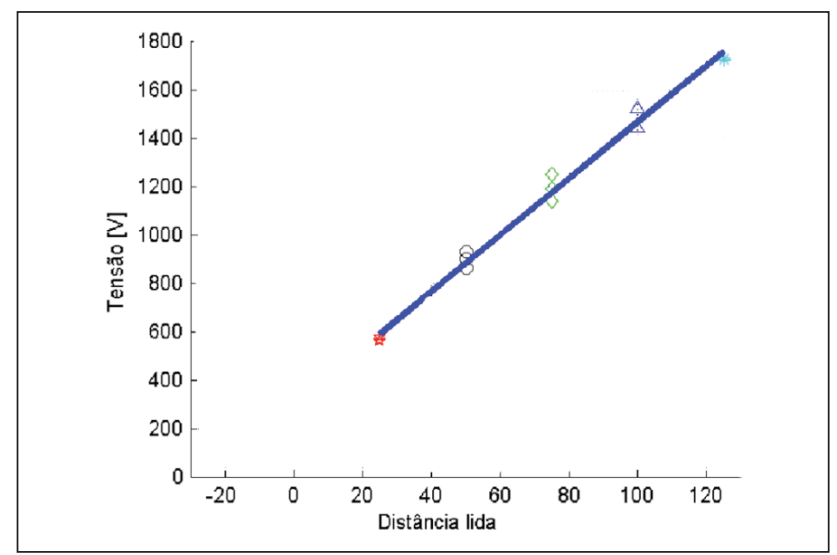

Figura 19: Tensão x distância lida no micrômetro

A partir da família de curvas obtidas, é possível também encontrar o valor do campo elétrico por meio do Método da Curva de Aproximação ${ }^{(35)}$,obtendo-se um gráfico de corrente de emissão versus campo elétrico E, conforme ilustrado na Figura 19.

A dispersão dos dados pode se relacionar com a variação das características do material emissor, com a imprecisão do modelo de capacitor plano adotado para se estimar o campo elétrico ou com a heterogeneidade dos emissores da amostra.

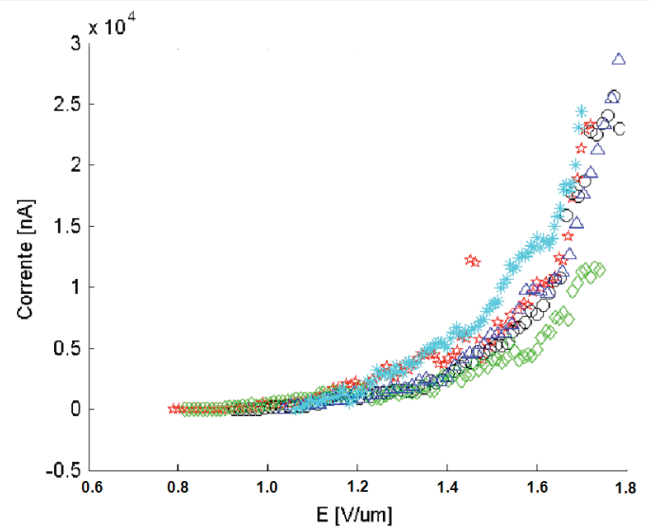

Figura 20: Corrente de emissão versus campo elétrico

\section{PERSPECTIVAS FUTURAS}

Vislumbra-se o contínuo desenvolvimento de rotinas automáticas para a realização de ensaios na câmara de vácuo. A partir da realização de reiterados ensaios de emissão de campo será possível determinar o ponto de tensão de pré-ruptura do vácuo em função da distância e material do substrato utilizado, bem como seus padrões de comportamento para, a partir daí, inseri-los como forma de "valor limite" na programação em Matlab, para que seja evitada a aplicação eventual de sobretensão à amostra e consequentemente a ocorrência de arco Voltaico.

Pode-se também examinar mais a fundo a possibilidade de se polarizar o eletrodo emissor (substrato), de forma a mitigar eventual emissão secundária, pois assim o potencial do substrato seria distinto do potencial do corpo da câmara de vácuo ${ }^{(36-38)}$.

Uma nova versão do circuito de medição da corrente de emissão eletrônica, utilizando-se um conversor do tipo sigma-delta e o restante da topologia descrita neste trabalho pode ser interessante para fins de comparação de desempenho. Vislumbra-se também dar continuidade ao trabalho por meio do desenvolvimento de automatismos eletromecânicos, de maneira a viabilizar os deslocamentos do anodo sobre a superfície da amostra, obedecendo a padrões geométricos, o que permitirá a alteração do software para levantamento do perfil de homogeneidade da emissão eletrônica ao longo da superfície da amostra.

\section{REFERÊNCIAS}

1. BARANAUSKAS, V.; PETERLEVITZ, A.C.; CERAGIOLI H.J., (2003). Advances in the chemical vapor deposition of diamond and diamond related materials. Activity Report (Laboratório Nacional de Luz Síncrotron), Vol. 1, No. 1; pp. 379-380.

2. BARANAUSKAS, V.; CERAGIOLI H.J.; PETERLEVITZ, A.C., (2003). Growth of self-supported diamond tubes in the hotfilament chemical vapor deposition system. Diamond and Related Materials, Vol. 12; pp. 346-349.

3. CERAGIOLI H.J.; PETERLEVITZ, A.C.; QUISPE, J.R.; BARANAUKAS, V., (2009). Growth and characterization of carbon nanofibers by a technique of polymer doped catalyst and hot filament vapor deposition. Vacuum. Vol. 83; pp. 273-275.

4. ZANIN, H.; MAY, P.W.; HAMANAKA, M.; CORAT, E.J., (2014) Field emission from hybrid diamond-like carbon and carbon nanotube composite structures. ACS applied materials \& interfaces. Vol. 5, No.23, pp 12238-12243

5. ZANIN, H.; CERAGIOLI, H.J.; PETERLEVITZ, A.C.; BARANAUSKAS, V. MARCIANO, F.M.; LOBO, A.O., (2015) Field emission properties of the graphenated carbon nanotube electrode Applied Surface Science vol. 324, pp. 174-178

6. BARANAUSKAS, $\quad V_{\text {.; }}$ FONTANA, M.; CERAGIOLI H.J; PETERLEVITZ, A.C., (2004). Nanostructured diamond and diamond-like materials for application in field emission devices. Nanotechnology Vol.15; pp. S678-S683.

7. JAVEY, A.; KONG, J., (2009). Carbon Nanotube Electronics. Series on Integrated Circuits and Systems. Ed. Springer. ISBN 0387368337. $267 \mathrm{p}$

8. ROOS, M., (2007). Emissão de elétrons por efeito de campo em diamante policristalino dopado com boro e desenvolvimento de um novo sistema de ultra alto vácuo, in Tese de Mestrado. Faculdade de Engenharia Elétrica e de Computação Universidade Estadual de Campinas: Campinas. 
9. DEGASPERI, F.T., (2006). Contribuições para análise, cálculo e modelagem de sistemas de vácuo. Departamento de Semicondutores, Instrumentos e Fotônica. Tese de Doutorado, Faculdade de Engenharia Elétrica e de Computação Universidade Estadual de Campinas: Campinas.

10. YAO, N.; WANG, Z.L., (2005). Handbook of microscopy for nanotechnology. Boston: Kluwer Academic Publishers. Xx, 731 p.

11. KLEINT, C., (1993). On the early history of field emission including attempts of tunneling spectroscopy. Progress in Surface Science, Vol. 42, No. 1-4; pp. 01-115.

12. LATHAM, R.V., (1995). High Voltage vacuum insulation: basic concepts and technological practice. Elsevier. ISBN 0124371752. $568 \mathrm{p}$.

13. SANSEN, W.M.C., (2006). Analog design essentials, Vol. 1. Springer. ISBN 0387257462. $777 \mathrm{p}$.

14. VAN VLIET, K.M.; VAN LEEUWEN, C.J.; BLOK, J.; RIS, C., (1954). Measurements on current noise in carbon resistors and in thermistors. Physica Vol. 20, No. 7; pp. 481-496.

15. CAMPBELL, R.H.J.; CHIPMAN, R.A., (1949). Noise from currentcarrying resistors $20-500 \mathrm{KC}$. Proceedings of the IRE. Vol. 37, No. 8; pp. 938-942.

16. OTT, H.W., (2009). Electromagnetic Compatibility Engineering. John Wiley and Sons. ISBN 0470189304. 872 p.

17. KESTER, W., (1999). Practical Design Techniques for Sensor Signal Conditioning. Analog Devices. ISBN 0916550206.

18. FRANCO, S., (2002). Design with operational amplifiers and analog integrated circuits. 3rd ed. McGraw-Hill series in electrical and computer engineering. New York: McGraw-Hill. xiv, 658 p.

19. INSTRUMENTS, K., (2010). Low level measurements handbook precision DC current, Voltage, and resistance measurements, 6 ed.

20. JOHNSON, M., (2003). Photodetection and measurement: maximizing performance in optical systems. McGraw-Hill professional engineering, New York: McGraw-Hill. xiii, ISBN 0071409440. 298 p.

21. HOBBS, P.C.D., (2009). Building electro-optical system: Making it all work. 2nd ed: Wiley. ISBN 111821109X. 820p.

22. GRAY, P.R., (2009). Analysis and Design of Analog Integrated Circuits. John Wiley \& Sons. ISBN 0470245999. 896 p.

23. ALLEN, C.R., (1973). Low-drift integrator circuit. IEEE Journal of Solid-State Circuits Vol. 8, No. 3; pp. 236-237.6,7

24. STEVENS, A.E.; G.A. MILLER, G.A., (1994). A high-slew integrator for switched-capacitor circuits. IEEE Journal of SolidState Circuits Vol. 29, No. 9; pp. 1146-1149.

25. WEBSTER, J.G., (1999). The measurement, instrumentation, and sensors handbook. The electrical engineering handbook series,
Boca Raton, Fla.: CRC Press published in cooperation with IEEE Press. Springer. ISBN 3540648305. 1500 p.

26. PEASE, R.A., (1991). Troubleshooting analog circuits. EDN series for design engineers. Boston: Butterworth-Heinemann. Xii, ISBN 0750694998. $217 \mathrm{p}$

27. PEASE, R.A. (2008)., Analog circuits. Newnes world class designs series, Amsterdam ; Boston: Newnes/Elsevier. xxiii, ISBN 0750686278. $436 \mathrm{p}$.

28. YAMAZAKI, K.; KATO, K.; MURAMATSU, K.; HAGA, A. KOBAYASHI, K.; KAMATA, K.; FUJIWARA, K.; YAMAGUCHI, T. (2005). Incremental permeability of mu-metal in low magnetic fields for the design of multilayer-type magnetically shielded rooms. Magnetics, IEEE Transactions on Magnetics Vol. 41, No. 10; pp. 4087-4089.

29. SANG-BEOM, K.; JOON-YOUNG, S.; KOO-YONG, S.; JIN-HYE, J.; SUNG-HO, M., (2010). Magnetic Shielding Performance of Thin Metal Sheets Near Power Cables. IEEE Transactions on Magnetics Vol. 46, No. 2; pp. 682-685.

30. KESTER, W., (2005). Data conversion handbook. Analog Devices series. Elsevier. ISBN 0750678410. 953 p.

31. KUO, S.M.; MORGAN, D.R., (1999). Active noise control: a tutoria review. Proceedings of the leee Vol. 87, No. 6; pp. 943-973.

32. DALL'AGNOL, F.F.; PAULO, A..C.; PAREDES, P.; ENGELSEN D.; SANTOS, T.E.A.; MAMMANA, V.P., (2010). Method to obtain nonuniformity information from field emission behavior. Journa of Vacuum Science \& Technology B, 2010. Vol. 28, No. 3; pp. 441-449

33. ZANIN, H.; SAITO, E.; MARCIANO, F.R.; CERAGIOLI, H.J.; GRANATO, A.E.C.; PORCIONATTO, M.; LOBO A.O., (2014) Fast preparation of nano-hydroxyapatite/superhydrophilic reduced graphene oxide composites for bioactive applications Journal of Materials Chemistry B Vol. 1, No. 38, pp. 4947-4955

34. PAULO, A.C., (2011). Método para avaliar as propriedades de emissão de materiais nanoestruturados. Dissertação (Mestrado em Ciência e Tecnologia de Materiais e Sensores) - Instituto Nacional de Pesquisas Espaciais, São José dos Campos.

35. MAMMANA, V.P.; MONTEIRO, O.R.; FONSECA, L.R.C., (2004) Approach curve method for large anode-cathode distances. Journal of Vacuum Science \& Technology B: Microelectronics and Nanometer Structures, Vol. 22, No. 2; pp. 715-720.

36. BANCROFT, W.H., (1956) Design considerations for secondary electron emission studies with a mass spectrometer. $82 \mathrm{p}$.

37. NATION, J.A.; SCHACHTER, L.; MAKO, F.M.; LEN, L.K.; PETER, W.; CHA-MEI T.; SRINIVASAN-RAO, T.. (1999). Advances in cold cathode physics and technology. Proceedings of the IEEE Vol 87 , No. 5; pp. 865-889.

38. MOTOYAMA, Y.; MATSUZAKI, H.; MURAKAMI, H., (2001). Study of the secondary electron yield \&gamma; of insulator cathodes for plasma display panels. Electron Devices, IEEE Transactions on Electron Devices Vol. 48, No. 8; pp. 1568-1574. 